\title{
Gluconeogenic enzyme gene expression is decreased by dietary carbohydrates in common carp (Cyprinus carpio) and gilthead seabream (Sparus aurata) $^{*^{1}}$
}

\author{
S. Panserat*, E. Plagnes-Juan and S. Kaushik \\ Laboratory of Fish Nutrition, INRA-IFREMER, 64310 St-Pée-sur-Nivelle, France \\ *panserat@st-pee.inra.fr Tel.: +33-5-59-51-59-99; fax: +33-5-59-54-51-52
}

\begin{abstract}
Our objective is to understand the low metabolic utilization of dietary carbohydrates in fish. We compared the regulation of gluconeogenic enzymes at a molecular level in two fish species, the common carp (Cyprinus carpio) and gilthead seabream (Sparus aurata), known to be relatively tolerant to dietary carbohydrates. After cloning of partial cDNA sequences for three key gluconeogenic enzymes (glucose-6-phosphatase (G6Pase), fructose biphosphatase (FBPase) and phosphoenolpyruvate carboxykinase (PEPCK) in the two species, we analyzed gene expressions of these enzymes 6 and $24 \mathrm{~h}$ after feeding with (20\%) or without carbohydrates. Our data show that there is at least one gluconeogenic enzyme strongly regulated (decreased expression after feeding) in the two fish species, i.e. the PEPCK for common carp and G6Pase/FBPase for gilthead seabream. In these fish species, the regulation seems to be similar to the mammals at least at the molecular level.
\end{abstract}

Keywords: Dietary carbohydrate; Hepatic glucose metabolism; Gene expression; Gluconeogenesis; Common carp; Gilthead seabream 


\section{INTRODUCTION}

Improvement of dietary carbohydrate utilisation by fish has practical implications in aquaculture. Salmonids show low carbohydrate utilisation $[1,2,3,4,5,6]$. Analysis of glucose phosphorylation $[2,3,7]$, glucose transporter $[8,9,10]$ and insulin receptors $[11$, 12] in target tissues is important in order to obtain an overall view of low dietary glucose utilisation. One additional hypothesis to explain the poor utilisation of dietary glucose by rainbow trout is a persistent highly active hepatic glucose production even when fed diets with high levels of carbohydrates [6]. We recently showed in rainbow trout the induction of the first glycolytic enzyme, the glucokinase (E.C. 2.7.1.2), as well as the absence of inhibition of gene expressions for enzymes implied in the hepatic glucose production, i.e. the glucose-6-phosphatase (G6Pase, EC 3.1.3.9), the phosphoenolpyruvate carboxykinase (PEPCK, EC 4.1.1.32) and the fructose-1.6bisphosphatase (FBPase, EC 3.1.3.11) by dietary carbohydrates $[7,13,14,15]$. In mammals, all the gluconeogenic enzymes are primarily regulated by dietary carbohydrate intake by decreasing the amount of the protein [16]. While FBPase and G6Pase are also subject to short-term regulation via allosteric or covalent modification of the enzyme $[16,17]$, the PEPCK is the only enzyme regulated only at the stage of enzyme production [18]. Overall, in mammals, G6Pase, FBPase and PEPCK enzyme contents generally correlate with the amount of the corresponding mRNAs and there is decreased gene expression for these hepatic enzymes by refeeding carbohydrates [16] in contrast to what we previously observed in rainbow trout. 
In contrast to the carnivorous rainbow trout, common carp (Cyprinus carpio), an omnivorous fish, utilizes easily high levels of dietary carbohydrates and gilthead seabream (Sparus aurata), a marine carnivorous fish, has an intermediary phenotype $[19,20,21,7]$. Indeed, in common carp fed with $20 \%$ of digestible carbohydrates, there is no postprandial hyperglycemia whereas in gilthead seabream, the hyperglycemic response is not persistent ( $24 \mathrm{~h}$ after feeding, the glycemia drops up to pre-feeding values) [7]. We hypothesized that the lack of molecular inhibition of gluconeogenic enzyme gene expression observed in rainbow trout which can at least partially explain its low dietary carbohydrate utilization is specific to this species and will not be found in carp and seabream. Thus, the first step was to clone partially cDNAs for each PEPCK, FBPase and G6Pase enzymes in common carp and gilthead seabream using degenerated primers for RT-PCR. The second step was to analyze gene expression in the liver $6 \mathrm{~h}$ and $24 \mathrm{~h}$ after feeding with or without carbohydrates by Northern blotting. 


\section{MATERIAL AND METHODS}

\section{Fish and diets}

Juvenile immature Common carp (Cyprinus carpio) and gilthead seabream (Sparus aurata) were reared respectively at the INRA experimental fish farm (Saint-Pée-surNivelle, France) at the ICBAS experimental fish farms (Vila Real and Olhao, Portugal) having an average of body weight of about $150 \mathrm{~g}$. Fish were grown for 10 weeks at $18^{\circ} \mathrm{C}$ (carp) and $25^{\circ} \mathrm{C}$ (gilthead seabream) during spring (common carp) and autumn (gilthead seabream) under natural photoperiods. They were fed twice a day to near satiation with formulated dry diets containing high levels of digestible carbohydrates $(>20 \%)$ or diets without carbohydrates (<0.5\%), as described previously [7]. On the day of sampling, fish were fed once and sacrificed 6 hours and 24 hours after feeding by a blow on the head. Liver from fish was quickly removed, frozen in liquid nitrogen and stored at $-80^{\circ} \mathrm{C}$.

\section{RNA isolation and reverse transcription.}

Total RNA was extracted as described by Chomczynski and Sacchi [22]. cDNA was obtained by annealing $3 \mu$ l of total RNA (fish fed without carbohydrates sacrificed 24 hours after feeding) with $0.25 \mu \mathrm{g}$ of random primers and $0.25 \mu \mathrm{g}$ of Oligo (dT) $)_{15}$ primer, and incubating with AMV reverse transcriptase (Promega,USA) for 10 minutes at $25^{\circ} \mathrm{C}$ and $1 \mathrm{~h}$ at $42^{\circ} \mathrm{C}$.

\section{Cloning of partial PEPCK, FBPase and G6Pase cDNAs}


PEPCK, FBPase and G6Pase sequences from different species were compared using the Clustal-W multiple alignment algorithm [23]. The sequences of the upstream and downstream (degenerate) primers chosen on the highly conserved nucleotide sequence regions are presented in Table 1 . cDNA $(2 \mu l)$ was amplified by polymerase chain reaction (PCR) using $20 \mathrm{pmol}$ of the degenerate primers in a reaction mixture containing $1.5 \mathrm{mM} \mathrm{MgCl}_{2}, 50 \mathrm{mM} \mathrm{KCl}, 10 \mathrm{mM}$ Tris- $\mathrm{HCl}, 0.1 \%$ triton X-100, $0.2 \mathrm{mM} \mathrm{dNTP}$, and 1 Unit of Taq polymerase (Promega, USA). Thirty-five cycles of denaturation at $94^{\circ} \mathrm{C}$ for 20s, specific temperature of annealing (see Table 1) for $20 \mathrm{~s}$, and extension at $72^{\circ} \mathrm{C}$ for 20s were performed. PCR products were subjected to electrophoresis in $1 \%$ agarose gels and fragments of the expected size range were purified (Amicon, Millipore corporation, USA). The purified DNA fragments were inserted into the $\mathrm{PCR}^{\circledR} 2.1$ TOPO plasmid and used for transformation of TOP10 One Shot ${ }^{\circledR}$ chemically competent cells (Invitrogen, Carlsbad, CA, USA). Inserts were detected by EcoRI digestion of the extracted plasmid DNA. Two clones with inserts were sequenced (Cybergène, Evry, France).

\section{Sequence analysis}

Nucleotide sequences were compared with DNA sequences from the Genbank database using the basic local alignment search tool (BLAST) algorithm [24]. Sequence alignments and percentage of amino acid conservation were assessed with the ClustalW multiple alignment algorithm using the cloned fish sequence and sequences from other species corresponding to the amplified regions from databases. 


\section{Analysis of gene expression (Northern blot)}

Extracted total RNA $(20 \mu \mathrm{g})$ samples were electrophoresed in 1\% agarose gels containing 5\% formaldehyde and capillary transferred onto nylon membranes (Hybond$\mathrm{N}^{+}$, Amersham, England). After transfer, RNA blots were stained with Methylene Blue to locate $26 \mathrm{~S}$ and $16 \mathrm{~S}$ rRNAs and to determine the relative amount of loaded RNA. Membranes were hybridized with seabream or carp $\left[{ }^{32} \mathrm{P}\right]$-labeled DNA probes (specific for each cDNAs sequence) labeled by random priming (Stratagene, USA). After stringent washing (2X SSC, $0.1 \%$ SDS for $20 \mathrm{~min}$; $1 \mathrm{X}$ SSC, $0.1 \%$ SDS for $20 \mathrm{~min} ; 0.2 \mathrm{X}$ SSC, $0.1 \%$ SDS for $15 \mathrm{~min}$ ), the membranes were exposed to X-ray film and the resulting images were quantified using Visio-Mic II software (Genomic, France).

\section{Statistical analysis}

The results are expressed as the means \pm standard deviation (SD). When there were significant differences of variances (one-way Anova test), statistical differences between series of data were determined using Tukey's post-hoc test (Systat 9 software products, SPSS Inc.). Differences were considered significant at the level of $5 \%$. 


\section{RESULTS}

The available G6Pase, FBPase and PEPCK cDNA sequences were aligned and highly conserved regions from different species including rainbow trout were identified. Several sets of primers were designed (Table 1 ) and made it possible to partially amplify G6Pase, FBPase and PEPCK mRNAs in common carp and gilthead seabream. RTPCR were performed on hepatic total RNA extracted from fish fed without carbohydrates 24h after feeding. PCR conditions were optimized and a major amplification product of the expected size were obtained for G6Pase, FBPase and PEPCK genes in each fish species (data not shown). The PCR fragments were purified, cloned and sequenced. The cDNA sequences of 224 bp (carp and seabream G6Pase), 395 bp/164 bp (carp FBPase and seabream FBPase respectively), 1262 bp/ 405 bp (carp PEPCK and seabream PEPCK respectively) were highly similar to those of trout genes (Blast algorithm, $p=10^{-12}$ to $10^{-4} / p=10^{-12}$ to $10^{-8}, p=10^{-15}$ to $10^{-4} / p=10^{-12}$ to $10^{-8}, p=10^{-68}$ to $10^{-}$ $5 / p=10^{-12}$ to $10^{-8}$ for carp/seabream G6Pase, FBPase and PEPCKs respectively). The corresponding amino acid sequences were deduced from the six cDNA sequences showing an open reading frame of 74 (carp and seabream G6Pase), 131/54 (carp FBPase and seabream FBPase respectively) and 418/134 (carp PEPCK and seabream PEPCK respectively) codons highly homologous to mammalian and trout proteins (Blast algorithm, $p=10^{-21}$ to $10^{-17} / p=10^{-25}$ to $10^{-22}, p=10^{-59}$ to $10^{-26} / p=10^{-19}$ to $10^{-9}, p=0 / p=10^{-60}$ to $10^{-39}$ for carp/seabream G6Pase, FBPase and PEPCK respectively) (Figure 1). Although direct evidence that these teleostean enzyme cDNAs correspond to functional enzymes is lacking, the nucleotide and amino acid sequence homology with mammalian 
sequences and known observation of a hepatic gluconeogenic enzyme activity in teleosts are in favour of the existence of functional enzymes in these species.

As growth rates and feed utilization of common carp and gilthead seabream fed with (20\%) or without carbohydrates were comparable (Panserat et al., 2000), comparative analysis of the effect of dietary carbohydrates on the regulation of G6Pase, FBPase and PEPCK enzyme expressions between fish groups fed different carbohydrate levels was possible. G6Pase, FBPase and PEPCK cDNA gene expressions were analyzed in fish livers by Northern blotting. A single mRNA species for each of the cDNAs in common carp and gilthead seabream were found (Figures 2 and 3) : G6Pase and PEPCK were of approx. $1.5 \mathrm{~kb} / 2.6 \mathrm{~kb}$ of size respectively in the two fish species whereas FBPase mRNAs were about $1.6 \mathrm{~kb}$ or $1.4 \mathrm{~kb}$ for carp and seabream respectively. The effect of feeding carbohydrates on G6Pase, FBPase and PEPCK gene expressions was analyzed 6h and 24h after feeding: a) in common carp, in contrast to the G6Pase and FBPase gene expression (for which, there were no significant differences between fish fed with or without carbohydrates), the level of PEPCK mRNA was significantly higher 24h after feeding carbohydrates than 6h after feeding ( $p<0.05$, Tukey's test) (Figures 2a, $2 b, 2 c) ; b$ ) in gilthead seabream, the PEPCK gene was expressed at the same level independently of the postprandial time and the diet; in contrast, there were lower G6Pase and FBPase gene expression 6h after feeding carbohydrates compared to fish fed without carbohydrates ( $<<0.05$, Tukey's test) (Figures 3a, 3b, 3c). Moreover, there is even no detectable level of G6Pase gene expression $6 \mathrm{~h}$ after feeding carbohydrates. 


\section{DISCUSSION}

G6Pase, FBPase and PEPCK belong to a family of enzymes, such as L-type pyruvate kinase (E.C.2.7.1.40), glucokinase (E.C.2.7.1.1) and fatty acid synthetase (E.C.2.3.1.85) known to be regulated by dietary carbohydrates in mammals [16]; overall, the gluconeogenic enzyme gene expressions are decreased (at the enzymatic and molecular levels) by feeding with dietary carbohydrates in mammals [16]. We cloned partially cDNAs coding for these enzymes in two fish species in order to analyse the nutritional regulation of their expression and to compare it with the 'glucose intolerant' rainbow trout, having an absence of inhibition of the gluconeogenic pathway by dietary glucose at least at the molecular level $[13,14,15]$. The high levels of similarity (up to $80 \%$ ) between the cDNA nucleotide sequences of G6Pase, FBPase and PEPCK in common carp and gilthead seabream and the sequences from other vertebrates and rainbow trout suggest strongly that these sequences correspond to functional enzymes.

During the preparation of this manuscript a new full-length seabream G6Pase cDNA sequence was submitted to Genbank by Dr Baanante (university of Barcelona, Spain) (genbank accession number : AF151718); the comparison between these two sequences shows $78 \%$ of homology with mismatches found all along the sequence. This result suggests that the two G6Pase cDNA sequences correspond to two different genes in gilthead seabream; it is not really surprising because our protocol for cloning was not exhaustive and only 2 clones have been sequenced. Moreover, in the present Northern blot studies, it could not be possible to discriminate between the two G6Pase mRNA species if the size of the mRNA species are the same. 
We analysed the nutritional regulation of G6Pase, FBPase and PEPCK gene expression by Northern blotting using the presently characterised species-homologous probes. We observed that there was at least one gluconeogenic enzyme for which the gene expression is decreased 6h after feeding; PEPCK in common carp irrespective of the diets and G6Pase/FBPase in gilthead seabream after feeding carbohydrates specifically. Overall, these data suggest that the gluconeogenic pathways may be down-regulated by feeding carbohydrates in these two fish species at least at the molecular level.

The present results on the effect of dietary carbohydrates on gluconeogenic enzymes are in contrast to what was observed in rainbow trout $[13,14,15]$, Atlantic salmon (Salmo salar) and perch (Perca fluviatilis) $[25,26]$. In rainbow trout, it is suspected that the poor utilisation by rainbow of excessive supply of dietary carbohydrates is exacerbated by a 'persistent' endogenous glucose production $[13,14,15]$. The present data about existence of an apparent inhibition of capacity of endogenous glucose production at the molecular level in the two species known to utilise dietary carbohydrates seems to confirm this hypothesis. Moreover, in both type 1 and type 2 diabetes, excessive hepatic glucose production is a major contributor to both fasting hyperglycaemia and the highly elevated postprandial hyperglycemia [27, 28]. Based on the present and previous studies, we conclude that the same phenomenon, i.e. excessive hepatic glucose production due to efficicent gluconeogenesis [29], can at least partially explain the difficulty of rainbow trout (in contrast to common carp and gilthead seabream) to control strictly the postprandial glycemia as well as to utilise the exogenous supply of glucose. Elevated portal free fatty acids from the visceral adiposity (which is the main site for fat storage in salmonids), a dysfunction of an hormonal signal 
as well as a deregulation of a key transcription factor for gluconeogenesis (such as PGC-1) $[30,31]$ may explain the absence of nutritional regulation of gluconeogenesis in rainbow trout and account for overproduction of liver glucose output. Further studies including data from fasting fish, enzyme activities and other nutritional and endocrine factors are necessary to confirm the present data.

In conclusion, contrary to persistent gene expression of the gluconeogenic enzymes in rainbow trout, in common carp and gilthead seabream the expression of at least one gluconeogenic enzyme gene is reduced, providing further evidence at a molecular level for interspecies differences in glucose homeostatic mechanisms.

\section{Acknowledgments:}

We thank J. Santinha for the maintenance of the gilthead seabream (Olhao, Portugal). This work was partly supported by the European Commission (Fisheries Agricultural and Agro-Industrial Research, Contract FAIR NCT95-074). 


\section{References}

1. BeRgot F., 1979. - Effects of dietary carbohydrates and of their mode of distribution on glycaemia in rainbow trout (Salmo gairdneri R.). Comp. Biochem. Physiol., 64A: 543-547.

2. COWEY C., WALTON M., 1989. - Intermediary metabolism In: Intermediary Metabolism Cowey C., \& Walton M., eds. pp. 259-329 Academic Press.

3. WILSON R, 1994 - Utilization of dietary carbohydrate by fish. Aquaculture, 124: 67-80.

4. MOON TW. \& FOSTER GD., 1995. - Tissue carbohydrate metabolism, gluconeogenesis and hormonal and environmental influences. In: Biochemistry and Molecular Biology of Fishes, Hochachka K. \& Mommsen TP., eds Elsevier vol 4 pp. 65-100.

5. Legate NJ, Bonen A, Moon TW, 2001 - Glucose tolerance and peripheral glucose utilisation in the rainbow trout, the american eel and the black bullhead catfish. Gen. Comp. Endocrinol. 122: 48-59.

6. Moon TW, 2001 - Glucose intolerance in fish: fact or fiction? Comp. Biochem. Physiol. Part B, 129: 243-249. 
7. Panserat S, Médale $F$, Blin C, Brèque J, Vachot C, Plagnes-Juan e, KRISHNAMOORTHY R, KAUSHIK S. 2000 - Hepatic glucokinase is induced by dietary carbohydrates in rainbow trout (Oncorhynchus mykiss), common carp (Cyprinus carpio) and gilthead seabream (Sparus aurata). Am J Physiol. 278 : R1164-1170.

8. Wright, J.R., O'Hali, W., Yuang, H., Han X., Bonen, A., 1998 - Glut4 deficiency and severe peripheral resistance to insulin in the teleost fish tilapia. Gen. Comp. Endocrinol. 111,20-27.

9. Planas, J.V., Capilla, E., Gutierrez, J., 2000. - Molecular identification of a glucose transporter from fish muscle. FEBS Lett. 481, 266-270.

10. Krasnov A, TeERIJOKI H, Molsa H, 2001 - Rainbow trout hepatic glucose transporter. Biochim. Biophys. Acta 91563: 1-5.

11. Mommsen TP., PlisetSkAYA EM., 1991. - Fish insulin: history, structure and metabolic regulation. Rev. Aquat. Sci., 4: 225-259.

12. Parrizas M., Planas J., Plisetskaya EM., Gutierrez J., 1994. - Insulin binding and receptor tyrosine kinase activity in skeletal muscle of carnivorous and omnivorous fish. Am. J. Physiol., 266: 1944-1950.

13. Panserat S, Médale F, Brèque J, Plagnes-Juan E, Kaushik S. 2000 - Lack of significant long-term effect of dietary carbohydrates on glucose-6-phosphatase 
expression in liver of rainbow trout (Oncorhynchus mykiss). J Nutr Biochem 11(1) : 22-29.

14. Panserat S., Plagnes-Juan E., Breque J., Kaushik S. 2001 - Hepatic phosphoenolpyruvate carboxykinase gene expression is not repressed by dietary carbohydrates in rainbow trout (Oncorhynchus mykiss). J exp. Biol 204: 359-365.

15. Panserat S., Plagnes-Juan E., Kaushik S. 2001 - Nutritional regulation and tissue specificity of gene expression for key proteins involved in hepatic glucose metabolism in rainbow trout (Oncorhynchus mykiss). J exp Biol 204 :2351-2360.

16. PILKIS, S.J., GRANNER, D.K. 1992 - Molecular physiology of the regulation of hepatic gluconeogenesis and glycolysis. Annu. Rev. Physiol. 54: 885-909.

17.Foster, J.D., Pederson, B.A., Nordlie, R.C. 1997. - Glucose-6-phosphatase structure, regulation and function : an update. Proc. Soc. Exp. Biol. Med. 215, 314332.

18. HANSON R.W., RESHEF, L. 1997 - Regulation of phosphoenolpyruvate carboxykinase (GTP) gene expression. Annu. Rev. Biochem. 66, 581-611.

19. FURUICHI M., YONE Y., 1982 - Effects of insulin on blood sugar levels in fishes Bull. Jpn. Soc. Sci. Fish., $48:$ 1289-1291. 
20. FURUICHI M., YONE Y., 1982 - Changes in activities of hepatic enzymes related to carbohydrate metabolism of fishes in glucose and insulin-glucose tolerance tests. Bull. Jpn. Soc. Sci. Fish., 48: 463-466.

21. Perres H., Goncalves P., Oliva-Teles A., 1999 - Glucose tolerance in gilthead seabream (Sparus aurata) and European seabass (Dicentrarchus labrax). Aquaculture 179: 415-423.

22. ChomczYNSKI, P. \& SACCHI, N. 1987. Single-step method of RNA isolation by acid guanidium thiocyanate-phenol-chloroform extraction. Anal. Biochem. 162(2) : 156159.

23. HIGGINS D, SHARP P 1989 - Fast and sensitive multiple sequence alignments on a microcomputer. CABIOS 5: 151-153.

24. Atlschul S, Gish W, Miller W, Myers E, Lipman D 1990 - Basic local alignment search tool. J. Mol. Biol. 215: 403-410.

25. Tranulis, M.A, Dregni, O., Christophersen, B., Krogdahl, A. \& Borrebaek, B. 1996. A glucokinase-like enzyme in the liver of atlantic salmon (Salmo salar) Comp. Biochem. Physiol. 114B (1) : 35-39. 
26. BorRebaek B, Christophersen B 2000- Heptaic glucose phosphorylating activities in perch (Perca fluviatilis) after diffrent dietary treatments. Comp. Biochem. Physiol. 125B: 387-395.

27. Mevorach M, Giacca A, Aharon Y, Hawkins M, Shamoon H, Rossetti L (1998) Regulation of endogenous glucose production by glucose per se is impaired in type 2 diabetes mellitus. J. Clin Invest. 102(4) : 744-753.

28. SALTIEL AR, 2001 - New perspectives into the molecular pathogenesis and treatment of type 2 diabetes. Cell 104: 517-529.

29. SuAREZ RK. \& MommSEN TP., 1987. - Gluconeogenesis in teleost fishes. Can. J. Zool. 65: 1869-1882.

30. Bergman RN, AdER M, 2000 - Free fatty acids and pathogenesis of type 2 diabetes mellitus. Trend in Endocrinol Metab. 9, 351-356.

31. Yoon JC, Puigserver P, Chen G., Donovan J., Wu Z, Rhee J., Adelman G., Stafford J., Kahn CR, Granner DK, Newgard CB, Spielgman BM, 2001 - Control of hepatic gluconeogenesis through the coactivator PGC-1. Nature 413: 131-138. 


\section{LEGENDS}

Figure 1. Partial cloning of the glucose-6-phosphatase (G6Pase) (a), fructose-1.6bisphosphatase (FBPase) (b) and phosphoenolpyruvate carboxykinase (PEPCK) (c) genes in common carp and gilthead seabream. Alignments of the partial amino acid deduced sequence from common carp and gilthead seabream with rainbow trout (Genbank accession numbers are : AF120150, AF333188 and AF246149 for G6Pase, FBPase and PEPCK in trout respectively).

Figure 2. Nutritional control of gluconeogenic gene expression in common carp. (a) glucose-6-phosphatase (G6Pase) (b) fructose-1.6-bisphosphatase (FBPase) (c) phosphoenolpyruvate carboxykinase (PEPCK). Representative northern blotting of gene expression in livers of fish food-deprived or fed fish with $20 \%$ of carbohydrates (+Cho) or without carbohydrates (-Cho). Each band is from a different fish. The $16 \mathrm{~S}$ rRNA served as internal control of sample loading . Values are means $\pm S D, n=5$ (except for PEPCK $(n=6)$ ). Significantly different means are represented by different letters (Tukey test, $\mathrm{p}<0.05$ ).

Figure 3. Nutritional control of gluconeogenic gene expression in gilthead seabream. (a) glucose-6-phosphatase (G6Pase) (b) fructose-1.6-bisphosphatase (FBPase) (c) phosphoenolpyruvate carboxykinase (PEPCK). Representative northern blotting of FBPase gene expression in livers of fish food-deprived or fed fish with $20 \%$ of carbohydrates (+Cho) or without carbohydrates (-Cho). Each band is from a 
different fish. The 16S rRNA served as internal control of sample loading . Values are means $\pm S D, n=5$ (except for FBPase $(n=6)$ ). Significantly different means are represented by different letters (Tukey test, $p<0.05$ ). 


\section{G6Pase-seabream \\ G6Pase-trout \\ G6Pase-carp}

G6Pase-seabream
G6Pase-trout
G6Pase-carp

G6Pase-seabream

G6Pase-seabreambaanante

G6Pase-seabream

G6Pase-seabreambaanante
VYLAAHFPHQVVAGVITGMIVAEAFDRTQWIYNASMKKYFYTTLFLTSFAVGFYLLLKAM VYMAAHFPHQVISGVITGIMVAEAFSRVQWIYGASLKKYFYTTLFLLSFAVGFYELLKAI VYMAAHFPHQVFAGVISGMVVAEAFNRQKWIYSASLKNYFNITLFLLSFAVALYLLLKAL

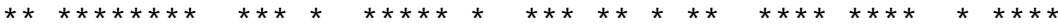

GVDLLWTLEKAQKW

GVDLLWSLEKAQKW

GVDLLWTLEKAQRW

b)

\author{
FBPase-seabream \\ FBPase-trout \\ FBPase-carp
}

FBPase-seabream FBPase-trout FBPase-carp

FBPase-seabream FBPase-trout FBPase-carp
VYLAAHFPHQVVAGVITGMIVAEAFDRTQWIYNASMKKYFYTTLFLTSFA VYMAAHFPHQVIAGVITGVLVAEVVSKEKWIYDASMRKYFHTTLSLTSLA $* * * * * * * * * * * * * * * * \quad * * *$

VGFYLLLKAMGVDLLWTLEKAQKW VGFYLLLRVLGVDLLWTMEKAQKW

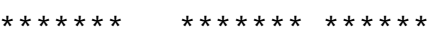

- - - - - - - - - - - - - - PLDGSSNIDCLVSIGTIFAIYRKTTDDEPNERDALQSGRHIVAAGYALYGSATMMVLSTG PLDGSSNIDCLASIGTIFAIYRKETDDEPSEKDALRSGRNIVAAGYALYGSATMLVLSTG

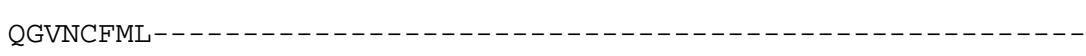
QGVNCFMLDPSIGEFILTDKDVKIKKRGKIYSLNEGFAQHFYPDVTEYLKKKKYPEDGSA QGVNCFMLDPAIGEFILVDQDVRIKKKGKIYSLNEGYAAHFYPDVTEYLQKKKFPEDGSS $* * * * * * * * * * * * * * * * * * * * * * * * * * * * * * * * * * * * * * * * * * * * * * * * *$ PYGGRYVGSMV

\section{Figure 1}




\author{
PEPCK-carp \\ PEPCK-trout \\ PEPCK-seabream
}

\author{
PEPCK-carp \\ PEPCK-trout \\ PEPCK-seabream
}

\author{
PEPCK-carp \\ PEPCK-trout \\ PEPCK-seabream
}

PEPCK-carp

PEPCK-trout

PEPCK-seabream

PEPCK-carp

PEPCK-trout

PEPCK-seabream

PEPCK-carp

PEPCK-trout

PEPCK-seabream

PEPCK-carp

PEPCK-trout

PEPCK-seabream
YDNCWLARTDPKDVARVESKTVIVTKDQRDTIPIPTGGAKSQLGSWMSEEPFQKAREDRF YENCWLARTDPKDVARVESKTVIVTKNQRDTIPIPDGGAKSQLGSWMSEGDFQKARQDRF

*

PGCMAGRTMYVIPFSMGPVNSSLAKFGVQVTDSPYVVASMGIMTRMGTPVLEKLAEGAEF PGCMSGRTMYVIPFSMGPVGSPLSKFGVQVTDSPYVVASMGIMTRMGTPVMDKLAQGAEF

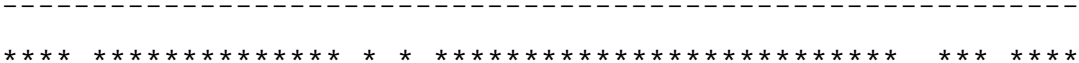

VRCQHSLGRPLPLKAPLVDSWPCNPDKVLISHLPDTRQILSFGSGYGGNSLLGKKCFALR VRCQHSLGRPLPLKAPLVNSWPCNPEKVLISHLPDTRQILSFGSGYGGNSLLGKKCFALR $* * * * * * * * * * * * * * * * * * \quad * * * * * * \quad * * * * * * * * * * * * * * * * * * * * * * * * * * * * * * * * * *$

IASRIAKDEGWLAEHMLILGITNPQGVKRYIAAAFPSACGKTNLAMMKPSLPGWTVECVG IASRIAKDEGWLAEHMLILGITNPQGVKRYVAAAFPSACGKTNLAMMKPALPGWTVECVG - GKTNLAMMKPSLPGWKVECVG

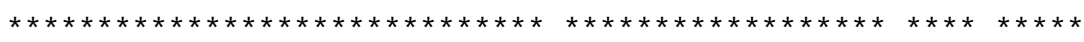

DDIAWMKFDSQGKLRAINPENGFFGVAPGTSLKTNPHAMATISRNTVFTNVGETSDGGVW DDIAWMKFDSQGKLRAINPENGFFGVAPGTSLKTNPHAMATIAKNTVFTNVGETSDGGVW DDIAWMKFDSQGKLRAINPENGFFGVAPGTSDKTNPYAMATIAKNTVFTNVGETSDGGVW $* * * * * * * * * * * * * * * * * * * * * * * * * * * * * * * * * * * * * * * * \quad * * * * * * * * * * * * * * * *$ WEGLEPPAPGIKLTDWHGKSWKYGDSTLCAHPNSRFCAPAGQCPI IDPLWESDEGVPIDA WEGLDPPAAGVSLTDWHGKSWKAGDSGPCAHPNSRFCTPAAQCPI IDPQWESDEGVPIDA WEGLAPPAAGVTLTDWHGKTWKQGSSTPCAHPNSRFCAPAGQCPIIDPQWESD - - - - - -

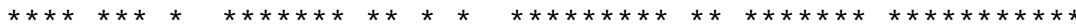

IVFGGRRPEGVPLVYESFNWRHGVFVGAAMRSESTAAAEHKGKVIMHDPFAMRPFFGYNF IIFGGRRPEGVPLVYESFNWRHGVFVGASMRSEATAAAEYKGKVIMHDPFAMRPFFGYNF

\section{Figure 1}


a)

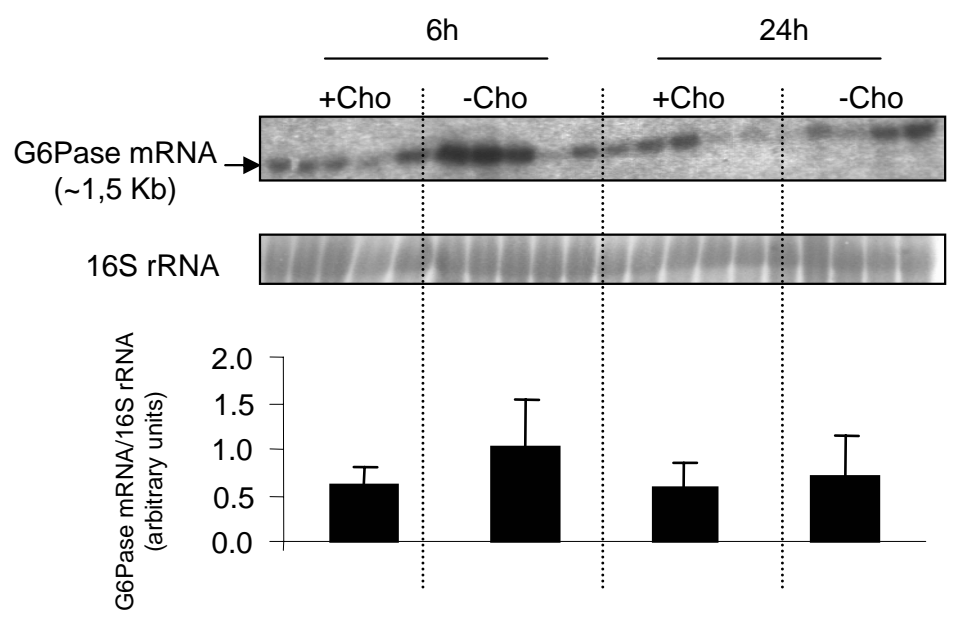

NS : non significant

b)
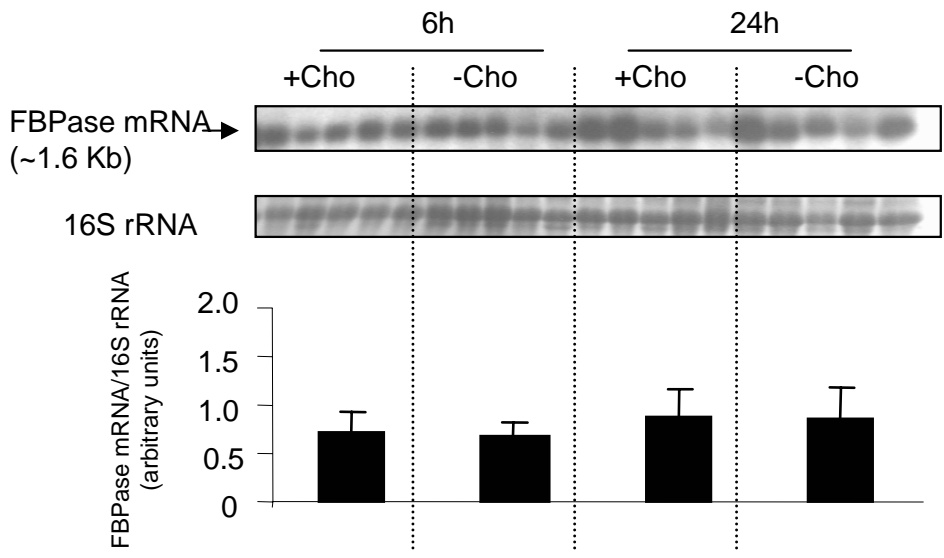

NS : non significant

c)

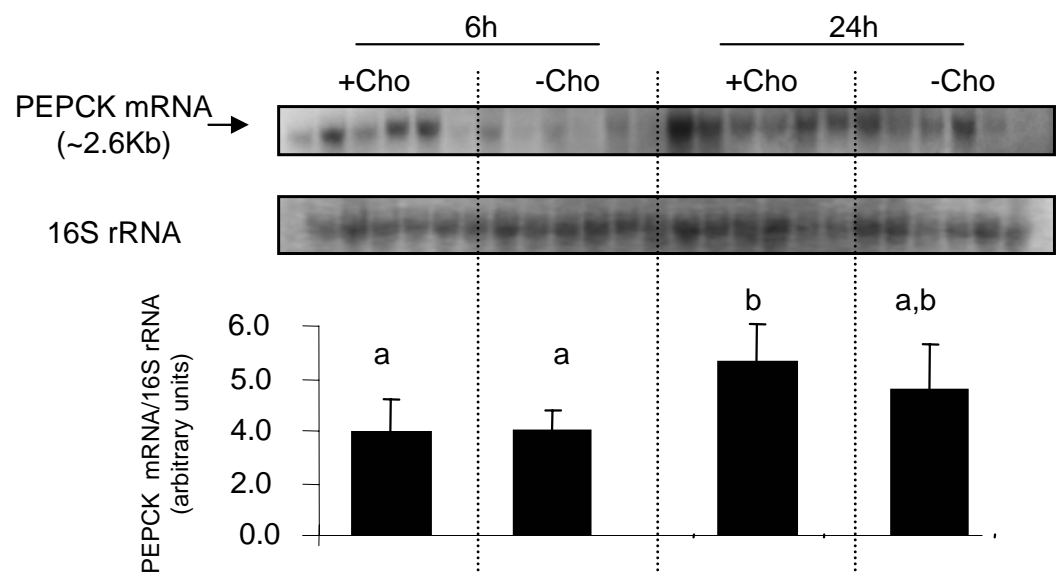

Figure 2 
a)

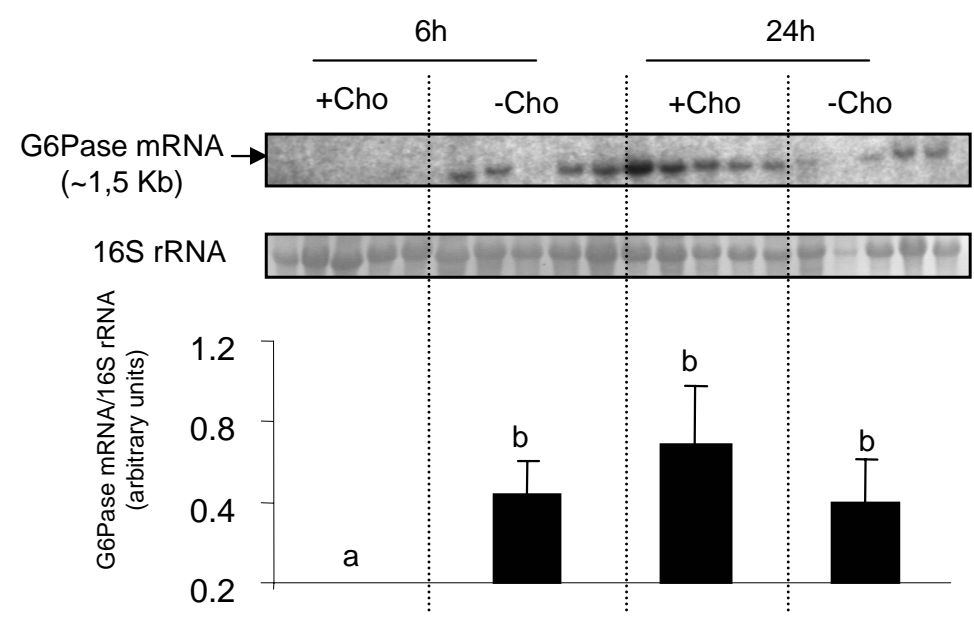

b)

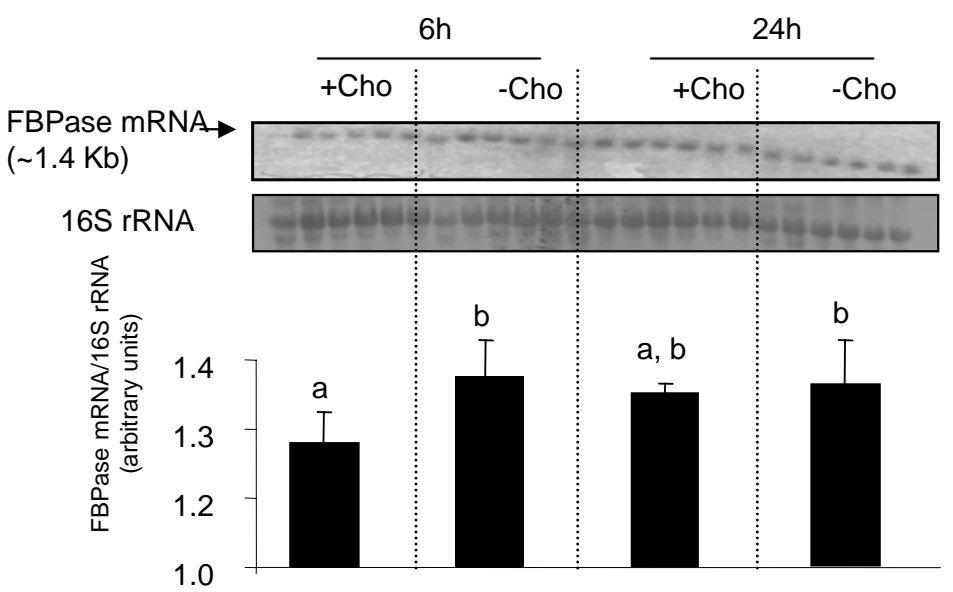

c)

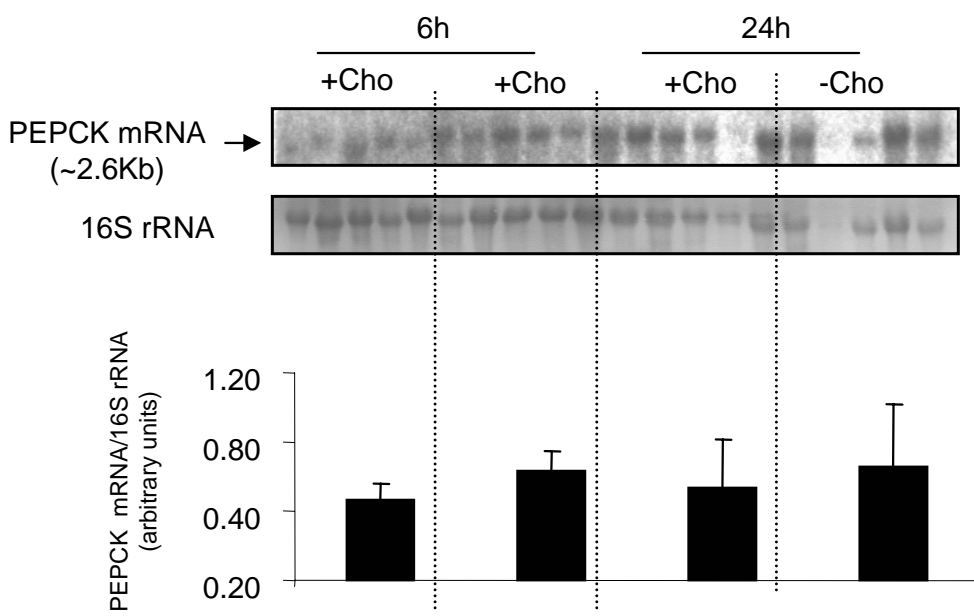

NS : non significant

Figure 3 
Table 1. Primers used for cDNA cloning and for RT-PCR analysis

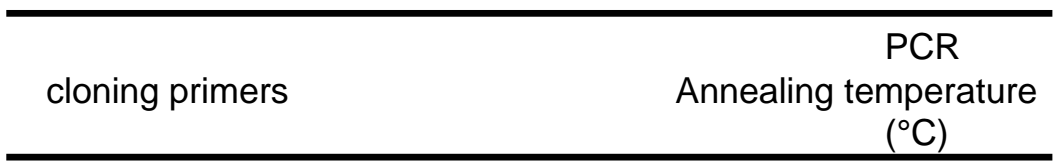

Gilthead seabream

\begin{tabular}{|c|c|c|}
\hline PEPCK & $\begin{array}{l}5 \text { '-GTGGGAAAACTAACCTGGCC-3' } \\
5 \text { '-TCGTCACTCTCCCACTGGGG-3, }\end{array}$ & $52^{\circ} \mathrm{C}$ \\
\hline FBPase & $\begin{array}{l}5 \text { '-GGACMATTTTTGSMATYTA-3' } \\
5 \text { '-TCMAGCATGAAGCAGTTGAC-3, }\end{array}$ & $50^{\circ} \mathrm{C}$ \\
\hline G6Pase & $\begin{array}{l}5 \text { '-RTCTACMTKGCTGCCYCAYTT-3' } \\
5 \text { '-ACCAYYTCTKGGCTTTCTCC-3' }\end{array}$ & \\
\hline
\end{tabular}

Common carp

\begin{tabular}{|c|c|c|}
\hline PEPCK & $\begin{array}{l}5 \text { '-TAYRAYAAYTGCTGGYTGGC-3', } \\
5 \text { '-CCRAARTTGTAGCCAAARAA-3' }\end{array}$ & $51^{\circ} \mathrm{C}$ \\
\hline FBPase & $\begin{array}{l}5 \text { '-CCMYTKGATGGMTCWTCCAA-3' } \\
5 \text { '-GCMACCATSGASCCSACATA-3, }\end{array}$ & $55^{\circ} \mathrm{C}$ \\
\hline G6Pase & $\begin{array}{l}5 \text { '-RTCTACMTKGCTGCCYCAYTT-3' } \\
5 \text { '-ACCAYYTCTKGGCTTTCTCC-3' }\end{array}$ & $52^{\circ} \mathrm{C}$ \\
\hline
\end{tabular}

